\title{
GERENCIANDO PROGRAMAS DE COMPENSAÇÃO AMBIENTAL DE USINAS HIDRELÉTRICAS: RELATO DE UMA EXPERIÊNCIA INDÍGENA NO PROCAMBIX
}

SYLVIA SALLA SETUBAL ${ }^{1}$

UFT

PAULO WAIKARNASE XERENTE ${ }^{2}$

$U F T$

ELINEIDE EUGÊNIO MARQUES ${ }^{3}$

UFT

SIMONE ATHAYDE ${ }^{4}$

UFT

RESUMO: A partir da análise dos documentos no processo de execução do Programa de Compensação Ambiental Xerente - Procambix e do desenvolvimento do Projeto Gestão Participativa da Biodiversidade em Terras Indígenas Atingidas por Barragens Hidrelétricas na Amazônia Brasileira (UFT/CAPES), surgiu a oportunidade de realizar esta entrevista com um indigena xerente que participou como gerente-executivo e membro do Conselho Gestor do programa. O objetivo da entrevista é apresentar a experiência de povos indígenas no processo de gestão e execução de programas de compensação ambiental de empreendimentos hidrelétricos, relatando suas dificuldades, apreensões e angústias, que permearam sua trajetória durante o desenvolvimento das ações do programa. O povo indígena Xerente vive nas Terras Indígenas (TI) Xerente e Funil, ocupando uma área de 184 mil hectares no município de

\footnotetext{
${ }^{1}$ Aluna da Pós-Graduação em Ciências do Ambiente da Universidade Federal do Tocantins - UFT. Professora do Instituto Federal do Tocantins Campus Palmas. E-mail: sylviasetubal@ifto.edu.br.

${ }^{2}$ Técnico em enfermagem e graduado em Administração pela Universidade do Tocantins (Unitins). Mestrando em Ciências do Ambiente pela Universidade Federal do Tocantins (UFT). Pertence à etnia Xerente.

${ }^{3}$ Professora, orientadora do Programa de Pós-Graduação em Ciências do Ambiente da Universidade Federal do Tocantins - UFT, Doutora em Ecologia de Ambientes Aquáticos Continentais pela Universidade Estadual de Maringá. É professora da Universidade Federal do Tocantins (UFT). E-mail: emarques@mail.uft.edu.br.

${ }^{4}$ Professora visitante no Programa de Pós-Graduação em Ciências do Ambiente da Universidade Federal do Tocantins - UFT, Doutora em Ecologia Interdisciplinar com concentração em Antropologia pela Universidade da Flórida. É professora e Pesquisadora no Programa de Conservação e Desenvolvimento Tropical do Centro de Estudos Latino-americanos da Universidade da Flórida. É professora visitante do Curso de Pós-Graduação em Ciências do Ambiente na Universidade Federal do Tocantins (UFT). E-mail: simonea@ufl.edu .
} 
Tocantínia, no estado do Tocantins. Apesar de serem identificados nos estudos de viabilidade da usina, não foram inseridos como população atingida do empreendimento para receber a mitigação dos impactos socioambientais. A entrevista com Paulo Waikarnase Xerente foi realizada em duas etapas, a primeira em outubro de 2016 e a segunda em 11 de agosto de 2017.

PALAVRAS-CHAVE: compensação ambiental; Xerente; co-gestão.

\begin{abstract}
From the analysis of the documents in the process of execution of the Xerente Environmental Compensation Program - Procambix, and the development of the Project for Participative Management of Biodiversity in Indigenous Lands Affected by Hydropower Dams in the Brazilian Amazon (UFT/CAPES), the opportunity arose for an interview with a native Xerente, who participated as executive manager and member of the Management Council of the program. The goal of the interview is to present the experience of Indigenous peoples in the process of management and execution of programs of environmental compensation for hydroelectric projects, reporting difficulties, apprehensions and anxieties that permeated their trajectory during the development of the program. The Xerente people live in the Xerente and Funil Indigenous Lands, occupying an area of 184,000 hectares in the municipality of Tocantinia, in the state of Tocantins, Brazil. Although they were identified in the feasibility studies for the plant, they were not included as a population affected by the project in order to receive the mitigation for socioenvironmental impacts. The interview with Paulo Waikarnase Xerente was conducted in two stages, the first in October 2016 and the second on August 11, 2017.
\end{abstract}

KEYWORDS: environmental compensation; Xerente; co-management.

\title{
Introdução
}

A partir da análise dos documentos no processo de execução do Programa de Compensação Ambiental Xerente (Procambix) e do desenvolvimento do Projeto Gestão Participativa da Biodiversidade em Terras Indígenas Atingidas por Barragens Hidrelétricas na Amazônia Brasileira (UFT/CAPES), surgiu a oportunidade de realizar esta entrevista com um indígena xerente, que participou como gerente-executivo e membro do Conselho Gestor no Procambix. O objetivo da entrevista é apresentar a experiência de povos indígenas no processo de gestão e execução de programas de compensação ambiental de empreendimentos hidrelétricos, relatando suas dificuldades, apreensões e angústias que permearam sua trajetória durante o desenvolvimento do programa. Busca-se também sensibilizar os gestores públicos para o aspecto da alteridade.

A entrevista aqui descrita, com Paulo Waikarnase Xerente, foi realizada em duas etapas. A primeira, em outubro de 2016, realizada em parceria com o Núcleo de Estudos em Assuntos Indígenas, NEAI, da UFT, campus Porto Nacional; e a segunda, em 11 de agosto de 2017, nas dependências do Núcleo de Pesquisa Aplicada à Pesca e Aquicultura do Tocantins (NUPA Norte 5) do IFTO, Campus Palmas. Ele pertence à etnia 
Xerente, é técnico em saúde e graduado em Administração Pública pela Universidade Estadual do Tocantins (Unitins).

\section{O Povo Xerente}

O povo indígena Xerente, junto com seus parentes Xavante e os Xacriabá, são falantes da língua akwe, do tronco linguístico Macro-Jê (MAYBURY-LEWIS, 1984). Estes povos pertencem à família Jê e são classificados a partir do ponto de vista de sua distribuição geográfica, como Jê Centrais. Enquanto os Kayapó, os Timbiras, os Suyás, os Krenakarorê ou Panará são classificados como Jê Setentrionais e, os Kaingang e os Xokleng como Jê Meridionais (Melatti, 2002, p 3 apud SILVA, 2006, p. 59). "A sociedade xerente é estabelecida por figuras duais que envolvem todos os aspectos de sua vida social: metades exogâmicas e cerimoniais, associações de idade, narrativas míticas, facções clânicas e cosmologia" (SCHROEDER, 2010, p. 67-68). Estudos de Nimuendaju (1942) descrevem que este povo se apresenta em metades, associadas à Lua e ao Sol. De um lado, estão os Isake (Sdakrã ou Wairi) que representam a Lua e do outro lado estão os Dohi (Siptato ou Dói) que representam o Sol. O lado Isake é subdividido em três clãs: Wahire, Krãiprehi e Krozake e, no lado Dohi, subdividido também em três clãs: o Kuzâ, Kbasi e Krito. "Estes clãs são identificados em suas pinturas corporais por traços e círculos, para os da Lua e do Sol respectivamente" (SCHROEDER, 2010, p. 67-68).

A etnia Xerente vive hoje em duas Terras Indígenas, denominadas Xerente e Funil, homologadas em 1972 e 1991 respectivamente. Elas ocupam uma área de 184 mil hectares no município de Tocantínia, localizado no estado do Tocantins, na região central do Brasil. Para Silva e Sousa (2015), o reconhecimento pelo Estado brasileiro dessas terras, em favor dos Akwe-Xerente, corresponde a uma ínfima parte do extenso território que eles ainda dominavam quando da chegada dos primeiros colonizadores aos cerrados da bacia Araguaia-Tocantins. A demarcação de suas terras é resultado de um processo longo, conturbado, marcado por tensões, lutas, violência e mortes.

Com a criação do estado do Tocantins, em 1989, pelo desmembramento da região norte do estado de Goiás, somada à instalação da capital na cidade de Miracema, vizinha da Terra Indígena, mas na margem do outro lado do Rio Tocantins, bem como a construção da futura capital Palmas, seu território ficou ainda mais cobiçado devido à sua localização estratégica, sendo foco das atenções regionais e nacionais.

\section{As Terras Xerente e os projetos de desenvolvimento econômico no seu entorno}


Hoje, as Terras Indígenas Xerente e Funil encontram-se rodeadas de projetos de desenvolvimento econômico, incentivados tanto pelo governo federal quanto pelo estadual, em parcerias com a iniciativa privada. Dentre eles, destacam-se os empreendimentos no município de Pedro Afonso, vizinho à terra indígena. O Prodecer III, projeto agrícola subsidiado pela Agência Internacional de Cooperação Japonesa - JICA, foi implementado no início da década de 90 para o plantio de soja e arroz de sequeiro. Posteriormente, a empresa norte-americana BUNGE veio para produzir álcool combustível, açúcar e energia elétrica em uma área de 24 mil hectares plantados e com projeção de atingir 32 mil hectares de canade-açúcar na região. Em 1998, sem que os Xerente tivessem assimilado os efeitos dos mencionados projetos agrícolas sobre o seu modo de vida, seus rituais e cosmologia, tem início o processo de construção da Usina Hidrelétrica Luís Eduardo Magalhães (usina de Lajeado). A usina é instalada no Rio Tocantins, na cidade vizinha de Lajeado, a $15 \mathrm{~km}$ de distância da área Funil. A hidrelétrica do Lajeado foi construída em tempo recorde: 39 meses (1998-2000), e o lago formado ocupa uma área total de $750 \mathrm{~km}^{2}$ no Rio Tocantins. A exploração da energia gerada é feita pelo consórcio Investco S.A, sendo a primeira usina formada por empresas privadas no Brasil.

A etnia xerente, apesar de ser identificada nos estudos de viabilidade da usina de Lajeado durante o processo de licenciamento ambiental, não foi inserida, como população atingida a jusante do empreendimento, em seus Estudos de Impactos Ambientais (EIA) e, tampouco foi incluída nos Programas Básicos Ambientais (PBAs) para receber a mitigação dos impactos socioambientais que viessem a sofrer em decorrência da obra.

\section{O Programa de Compensação Ambiental Xerente - Procambix}

O não reconhecimento pela empresa construtora Investco S.A da comunidade indígena xerente como atingida ou impactada da usina gerou conflitos e houve um longo período de negociação envolvendo entidades no apoio e na articulação. Dentre elas, podemos citar o Ministério Público Federal, o Ministério Público Estadual, a Fundação Nacional do Ín - Funai, o Instituto Brasileiro do Meio Ambiente e dos Recursos Naturais Renováveis - Ibama, o Instituto Natureza do Tocantins - Naturatins e o Conselho Indigenista Missionário - Cimi.

Finalmente, os Xerente foram reconhecidos como atingidos indiretamente pela usina Lajeado. Ficou estabelecido que a Investco deveria contratar uma empresa para realizar o Diagnóstico Etnoambiental dos Xerente com o objetivo de identificar os impactos que a usina causaria à comunidade. Este estudo foi feito pelos profissionais da ONG Operação Amazônia Nativa - Opan, do Centro de Estudos e Pesquisas do Pantanal, Amazônia e Cerrado - Gera, e da Universidade Federal do Mato Grosso. Os resultados do estudo nortearam o que poderia afetar a 
comunidade indígena de imediato, a médio e a longo prazo, sendo os resultados incluídos no documento intitulado Diagnóstico Etnoambiental das Terras indígenas Xerente e Funil (OPAN-GERA-UFMT- Investco, 2000). O Programa de Compensação Ambiental Xerente nasceu deste diagnóstico.

Tiveram início, então, as negociações sobre o valor e o teor das medidas compensatórias entre Investco e o povo Xerente. Como resultado ficou estabelecido que "o recurso financeiro seria de aproximadamente $\mathrm{R} \$ 10.000 .000,00$, a ser desembolsado ao longo de oito anos (20012008) em parcelas semestrais" (DE PAULA, 2000, p. 712). O gerenciamento desse recurso financeiro ficou a cargo do Departamento de Patrimônio Indígena da Funai, sendo o responsável pela operacionalização de gastos a Administração Regional da Funai (AER), instalada em Gurupi ${ }^{5}$. Ainda, no contexto de gerenciamento do recurso financeiro, foram criadas a Associação Indígena Akwe (AIA), responsável pela gestão de recursos humanos necessários ao andamento do programa, e o Conselho Deliberativo Interinstitucional, composto por representantes da população Xerente, da Funai, da Investco, do MPF, do Ibama e do Naturatins. O Conselho era paritário e "ficou responsável pela deliberação final dos Planos Anuais de Trabalho (PAT) do Procambix, bem como a fiscalização da aplicação dos recursos financeiros e do PAT" (DE PAULA, 2000, p. 712).

O diagnóstico indicou três eixos básicos que deveriam compor o Procambix, sendo estes: Cultura e Cidadania, para valorização das expressões culturais, apoio às novas formas de organização e garantia dos direitos à saúde e educação; Território e Recursos Naturais, para conservação e proteção das terras tradicionalmente ocupadas; e Segurança Alimentar e Geração de Renda, para maior disponibilidade de alimentos e alternativas de produção (DE PAULA, 2000, p. 712).

A seguir apresento o resultado das entrevistas realizadas com a liderança indígena Xerente Paulo Waikarnase Xerente.

Pesquisadora: Descreva sua experiência pessoal antes de assumir o cargo de Gerente Geral do Procambix.

Paulo Waikarnase Xerente: Meu nome é Paulo Waikarnase Xerente, sou xerente lá da Aldeia Porteira, lá eu nasci. Comecei minha vida estudantil na Escola Indígena Sremptowê, de primeira a terceira série. A quarta série, eu fiz na aldeia Bela Vista e, de quinta a oitava série, eu fiz no Colégio Batista, em Tocantínia, nos anos de [19]88 a 90. Depois eu fiz o ensino médio técnico em enfermagem em Miracema do Tocantins, na época, Miracema do Norte. Ingressei na Universidade, fiz Administração Pública

\footnotetext{
${ }^{5}$ Município tocantinense localizado a mais de $350 \mathrm{~km}$ das Terras Indígenas Xerente. 
pela Universidade Estadual do Tocantins, a Unitins. Daí, então, a gente começou a rastrear - fazer o traço da vida profissional. Ainda há muitas coisas que a gente tem que fazer. Quando terminei o curso de administração, fui para o cargo de assistente administrativo do governo do estado e, após, trabalhei na Secretaria de Assistência Social. Essa foi uma experiência que a gente tinha absorvido após o curso de administração. Mas uma coisa que foi realmente novidade foi $o$ Procambix, não só pra mim, mas para a comunidade como um todo, foi uma novidade muito grande.

Pesquisadora: Como este processo de construção da barragem e da usina, em um rio do porte do Tocantins, se desenhava na sua cabeça (na sua imaginação)?

Paulo Waikarnase Xerente: Então, nos anos de 1994-1996 ainda se falava que futuramente teria barragem no Rio Tocantins. Nós estivemos participando de debates na Câmara dos Deputados, em Brasília, e estavam falando lá. Nós estávamos numa sala e escutando: será que isso vai acontecer? Será? Como é que vai ficar a nossa vida? Nesta época eu tinha mais ou menos dezenove, vinte anos. Então para o povo indígena, o mundo branco já falava sobre fazer a barragem, e os mais velhos falavam: "cumé que vão fazer essa barragem no Rio Tocantins, sendo que é tão difícil aparar a água e vai fazer isso?" Sendo que já tinham feito a barragem de Tucuruí. E essa barragem de Tucuruí já teve impacto muito grande sobre a questão do nosso pescado no Rio Tocantins. Antigamente meu pai falava que muito rápido na beira do rio se pegava muito peixe, muito peixe. E hoje para pegar peixe passa o dia todo. Então, quer dizer, o impacto da barragem Tucuruí já atingiu o povo Xerente de imediato. Aí veio a barragem no Rio Tocantins, a montante da Terra Indígena, a dezessete quilômetros no Tocantins, acima da Terra Indígena, entre Miracema e Lajeado - a UHE Luis Eduardo Magalhães, a quarenta quilômetros de Palmas. Até quando isso aconteceu, nós já tínhamos a informação em Brasília, mas estávamos com a vista fechada, não estávamos entendendo o que estava acontecendo. Então isso aconteceu, e hoje o povo Xerente está sob a mira do impacto ambiental nas suas Terras Indígenas Xerente e Funil.

Pesquisadora: Como você se sentia ao participar de reuniões com os não indígenas, que pertenciam a diferentes órgãos e instituições, quanto aos discursos e falas sobre o processo de construção da usina?

Paulo Waikarnase Xerente: Foi uma realidade totalmente diferente, né? Uma coisa é você falar, e uma coisa é você ouvir sobre uma coisa que vai acontecer. Hoje está acontecendo. Como seria o Rio Tocantins 10 anos atrás e hoje? Vamos supor, daqui a 10 anos o que vai acontecer? O que foi falado ali pelos órgãos fiscalizadores, instituições que participavam do Conselho Fiscal dentro do programa, foi realmente uma novidade 
muito grande, né? Eles não tinham um exemplo claro que hoje se tem. Hoje, os anos já se passaram, o povo Xerente passou por este processo de aprendizado, de perda ou de ganho, mas passaram por este processo. Então, nós não tivemos em quem confiar sobre isso, com quem dialogar. E hoje somos referência, por exemplo, para os Apinajé, para os Krahô, outros indígenas do Mato Grosso e Pará já têm referência do Procambix. E eles já têm de onde ter uma visão do que vai acontecer. Os Xerente não, os Xerente não tinham muita experiência e a Funai também não, foi uma novidade para a Funai. Para os Xerente, foi uma coisa que na hora exata da reunião, do momento, nós não tivemos uma outra experiência que poderia complementar [informações] no nosso dia a dia das negociações. Porque nós não tínhamos um espelho de onde pudéssemos ver esse processo. Houve a marcha para Brasília e para a ver a usina Serra da Mesa. Para que nós compreendêssemos melhor como seria essa construção da barragem e como nós ficaríamos abaixo do grande reservatório de água. Isso foi muito importante, o povo Xerente se articular, o povo Xerente ter união, para entender o futuro que hoje está ali estabelecido para a Terra Indígena.

Pesquisadora: O que foi o Procambix? E como ele foi estruturado?

Paulo Waikarnase Xerente: Depois que saiu o EIA-RIMA da usina de Lajeado, nele estava escrito que a Terra Indígena Xerente não seria impactada, porque estava abaixo (jusante) da barragem e, por isso, o povo Xerente não seria inserido nos Programas Básicos Ambientais para efeito da mitigação dos impactos. Foi então que a Funai, junto com outros órgãos governamentais, como Ibama, Naturatins, MPF e o Cimi, fez articulação com o povo Xerente. Na época nós tínhamos mais ou menos 12 aldeias, sendo que na margem do Rio Tocantins eram 5 aldeias: a Funil, a Porteira, o Varjão, a Bela Vista e do Salto. Então, na visão, na ótica da empresa construtora, a Investco, somente poderiam ser compensadas as aldeias que estariam sendo afetadas diretamente, por estarem na margem do Rio Tocantins. Neste momento, entra a Funai para ajudar a negociação do povo indígena e entender o contexto de ser atingido ou não pela obra. O povo Xerente não deixa de ser impactado, pois o pessoal já fazia as roças de vazante nas margens do Tocantins. Após os períodos de enchente, desde muitos anos atrás, nossos antepassados já faziam. E, uma informação certa, repassada pelos técnicos da usina, é que as roças de vazante não iriam mais existir. O Programa de Compensação Ambiental Xerente, chamado de Procambix, aconteceu após muitas reuniões, às vezes internamente na comunidade, e outras junto com a Funai, com o Ministério Público. Tiveram audiências e comunicações, por um lado, com a empresa [Investco] do consórcio, e outras vezes com os órgãos fiscalizadores e instituições [Naturatins, Ibama, MPE, MPF] que também eram peças fundamentais para o bom andamento do programa. Apesar de todas essas reuniões, ninguém tinha experiência do que aconteceria no futuro e como seriam os acontecimentos no dia a dia do 
povo indígena após a barragem. Um indígena tinha um pouco de dificuldade de entendimento, tanto na parte da legislação (durante uma discussão que envolvia o tema sobre impacto ambiental), quanto nas questões dos impactos sociais que influenciariam culturalmente a vida da comunidade. Eles tinham uma dificuldade para entender um efeito tão abstrato, que não era real, que era imaginário. O resultado dos estudos que se encontram nos diagnósticos realizados pela Gera/Opan e outras instituições já norteavam os efeitos do barramento, que ia acontecer de imediato e o que poderia afetar a médio e longo prazo - mas para nós naquele momento, não fazia sentido. Então o Procambix foi o Programa de Compensação Ambiental Xerente para diminuir os impactos da usina, do qual tive o privilégio de participar da gestão. Durante oito anos, estive à frente deste programa, que, para mim foi um choque muito grande. Porque foi um programa com um valor, um recurso financeiro muito alto (eram 10 milhões de reais), sendo acompanhado por um Conselho Gestor, que era um tipo de órgão fiscalizador, onde os conselheiros aprovavam os recursos financeiros de um Plano Anual de Trabalho. Os conselheiros eram paritários; foram escolhidos cinco indígenas, representantes dos cinco postos indígenas existentes nas Terras Indígenas Xerente e Funil: um representante do Posto Indígena Xerente, um do Posto Indígena Brejo Comprido; um do Posto Indígena Brupré; um do Posto Indígena Rio do Sono e um do Posto Indígena Funil. E, por outro lado, nós tínhamos cinco representantes, sendo um da Funai - Tocantins; um da Funai - Brasília, um do MPF, um do Ibama, um do Naturatins, e as ONGs acompanhavam, principalmente o Cimi. Estas foram as instituições e pessoas que cristalizavam, que norteavam a aplicação dos recursos, a definição dos projetos e a contratação dos técnicos da época. A estrutura executora do programa foi organizada tendo uma gerência e mais três coordenações. A Coordenação de Cidadania e Cultura, a Coordenação de Meio Ambiente e a Coordenação de Produção e Comercialização - sendo contratado um agrônomo para atuar na área de produção e um engenheiro ambiental para a área de meio ambiente. Na área de cultura estavam os indígenas; eram dois na época; eu também fiz parte na Coordenação de Cultura no início, depois teve o Edvaldo Xerente e a Vanda Xerente; é importante citar suas contribuições. A proposta da Funai e da Investco para a gestão dos recursos financeiros, e que foi aprovada pelo Conselho Gestor, estava baseada na aplicação do recurso financeiro destinado ao Procambix, durante oito anos. Este recurso seria repassado pela Investco, que tinha a sede em São Paulo, para a Funai de Brasília. A Funai - Brasília recebia e mandava para Coordenação da Funai - Tocantins, na época localizada no município tocantinense de Gurupi. A coordenação da Funai - Tocantins repassava para a Associação Indígena Akwen - AIA, Associação Indígena Xerente, criada para realizar as contratações de pessoas físicas, a compra e aquisição dos materiais, dos equipamentos e dos insumos. Nós, os gerentes e coordenadores da estrutura executora, fomos contratados pela AIA; na época, o Vilmar era o presidente da associação. Depois, veio o Ribamar, duas vezes, então isso foi no decorrer de oito anos. Os 
recursos eram liberados a partir da elaboração do Plano Anual de Trabalho, que continha os projetos e ações a serem executadas. Essa proposta traçou o destino do recurso financeiro da compensação ambiental xerente, uma vez que o recurso, que era privado (destinado pela empresa privada), passa a ser público quando ele é incorporado aos recursos anuais da Funai, como sendo convênio. E, então, passa a ser regido pelos trâmites de compras públicas e todas as normas legais de uso de recursos públicos vigentes na época.

Pesquisadora: Qual a ideia de esperança, para o povo indígena Xerente, que o valor deste recurso financeiro trazia?

Paulo Waikarnase Xerente: Realmente o valor dez milhões de reais é um valor de dinheiro muito grande, mas que tinha um prazo de oito anos para serem gastos. Este recurso foi tratado em termos de projetos e não na forma do recurso em si e, para o povo Xerente, dez milhões de reais era dinheiro, muito dinheiro. A comunidade pensou sim que talvez este recurso nunca iria acabar. Na mente do povo Xerente, até hoje, há perguntas do tipo: "Esses dez milhões de reais para onde é que foi? Qual foi o projeto realizado que custou o recurso todo?"

Pesquisadora: Como foi prevista a execução do Procambix? Quais resultados ele trouxe para o povo Xerente?

Paulo Waikarnase Xerente: Todos os projetos previstos no Procambix eram organizados e detalhados no Plano Anual de Trabalho, chamado PAT. O Programa funcionava através das três coordenações: Cultura e Cidadania; Território e Recursos Naturais; e Segurança Alimentar e Geração de Renda, onde eram estabelecidos os projetos que seriam executados no PAT. Esses projetos foram incluídos no desenvolvimento da aplicação do recurso, no decorrer dos anos. Vou explicar as ações de cada uma, então. O repasse financeiro era feito anualmente pela Investco. Vinha um repasse de mais ou menos dois milhões de reais para o ano todo. E ali a gente já aplicava este recurso dentro do PAT aprovado. Depois que aplicasse esse recurso durante o ano, também fazíamos a prestação de contas. Neste também estavam inseridos os recursos da Funai, das próprias comunidades indígenas. Às vezes apresentávamos antes para os caciques nas aldeias. Lá no Brejo Comprido, por exemplo, reuniam-se todos os caciques e apresentávamos cada Plano, cada recurso, centavo por centavo. Depois trazíamos para Palmas e apresentávamos para os conselheiros. Na área de cultura, foi um trabalho muito bem feito, junto com a UFT (Universidade Federal do Tocantins) e a Secretaria de Educação em si. Foram muitos resgates, como por exemplo: o aprimoramento de um canto que estava em extinção; um clã, o Krãiprehi que estava assim meio apagado [desaparecendo], e que hoje, graças a Deus, já estão se pintando, se identificando [usando os grafismos deste clã]. Então isso foi um fruto que o Procambix alcançou. A Casa de Cultura 
Akwen também foi uma conquista, construída com recursos do programa [Procambix], na sede do município em Tocantínia; conta com várias salas e uma biblioteca. O programa alcançou os mais velhos [no sentido de reforçar a participação], como João Paulinho, João Calixto, os outros, mas não tem como citar todos. São os anciões que vieram contribuir na questão do fortalecimento da cultura xerente. Então, o programa em si, o valor não foi muito significativo, mas os frutos que ficaram, tais como a questão do fortalecimento da linguagem escrita, dos registros escritos dos cânticos, da história do povo Xerente, seus mitos, as festas [festa de dar nomes - Wakê; festa de homenagem aos mortos - Kuprê; festa do Padi - tamanduá bandeira; a corrida de toras], que haviam deixado de acontecer e, durante o desenvolvimento do programa, foram reativadas. Tudo isso está lá registrado nos documentos deixados na biblioteca, na Casa de Cultura Akwen, em Tocantínia. Na ação Território e Recursos Naturais, foi a fiscalização da Terra Indígena Xerente e a parte de monitoramento, da caça, da pesca e retirada das madeiras da área indígena. Tinham os postos de fiscalização, com carro, rádio de comunicação, tudo comprado com recursos do programa. A área da Segurança Alimentar e Geração de Renda envolvia a agricultura, a produção de animais (aves, suínos, peixes, bovinos) e foi estabelecida com o propósito de fornecer alimentos para a comunidade e comercializar o excedente. Esta área foi a mais preocupante, pois a roça mecanizada proposta foi muito questionada. Temos que lembrar que a Funai, na década de 70 de acordo com o estudo que foi feito, através do Serviço de Proteção aos Índios (SPI), já vinha fazendo a roça mecanizada e com tudo: trator e implementos agrícolas. Já vinham realizando este projeto de roça mecanizada, então foi uma coisa de dar continuidade ao projeto da Funai, mas com novas adaptações. Houve a participação do Ibama, que teria que autorizar para fazer um desmatamento de áreas onde iria ser cultivado, porque era um projeto que visualizava a questão de um impacto ambiental, e não tinha como fazer o projeto de roças mecanizadas de uma vez, sem essa análise. Então teve todo um processo para atender a legislação ambiental na Terra Indígena, que só o Ibama ou a Funai poderiam fazer. Então, a gente vê que hoje o povo era acostumado a fazer as suas roças de toco. Mas, no estudo, o diagnóstico apontou que isso tinha um impacto muito grande, que se fosse aprovado pela Investco fazer a roça de toco, talvez esse recurso que viria não seria aprovado, pois teria um impacto muito grande. Uma roça de três tarefas de uma família por exemplo, eles não têm cuidado de acerar, aí toca fogo ali e, se isso aí se alastra, o fogo sai do controle e pode queimar muitas terras. Os técnicos do Naturatins, Funai, Investco e Ruraltins se preocupavam com as leis ambientais e estavam prevendo a proteção da Terra Indígena. O projeto foi feito dentro da proteção ambiental e não se deveria incentivar a roça de toco. Antes disso e sempre, os índios já praticavam a roça de toco, só de toco, não tinha roça mecanizada. A cultura do povo Xerente em relação ao complemento agrícola é a roça de toco e a roça de vazante, essa última feita após as cheias do Rio Tocantins. O fogo dentro 
da cultura indígena era feito até para a caçada. Os mais velhos caçavam e mapeavam por onde andavam: "Ali, o animal tava andando por lá. Tá, o fogo fui eu que fiz. Nós colocamos fogo ali pra gente cercar os animais, pra gente matar e comer". Então essa é a história do fogo; tem até mito a respeito disso aí. Então, por exemplo, a roça de toco hoje é tida como degradante da parte ambiental. Na visão ambiental realmente é, mas dentro da nossa cultura isso já veio de longas datas. Para o povo Xerente, a cultura agrícola mesmo é a da roça de toco, mas no Programa de Compensação ela ficou proibida porque o uso do fogo causava prejuízo ao ambiente. A roça de vazante, que era outra categoria de roça realizada culturalmente, não iria mais ocorrer devido à construção da barragem, que não deixaria mais acontecer a enchente na vazante do rio. Então essa prática agrícola xerente foi impactada, desapareceu. Na aldeia Porteira, eu tinha a idade de mais ou menos 10, 11 anos quando eu vi a Funai fazendo roça mecanizada, e no programa repetiu-se tudo: o trator chegando, o desmatamento, aquele negócio todo; fizeram muita roça, nas regiões das aldeias Brupré, Funil, Brejo Comprido, Porteira e Rio do Sono também. Durante os anos em que o programa funcionou, foi o momento agrícola com roça mecanizada. Havia fartura de arroz nas aldeias, mas tudo que era necessário, tinha que ser atendido pelo programa: a compra dos tratores, os equipamentos, os insumos, a contratação de tratoristas, bem como a contratação dos técnicos agrícolas. Tudo era pago com recurso do programa. Foram feitas visitas técnicas, levaram os indígenas para conhecer o projeto. Por exemplo, quem escolheu piscicultura, levaram aqui em Brejinho do Nazaré, onde tem um criatório muito grande de peixe. Leva lá para o indígena olhar uma fazenda de gado, onde cria esta espécie de gado. Também foi feita a capacitação. O Ruraltins era para explicar como seria a questão da criação. Alguns foram até na Agrotins ${ }^{6}$, participar de palestras, aprender a criação de galinhas, tudo isso aí. Então teve essa participação antes, mas o projeto foi feito para atender à demanda de quem quisesse ter. Agora, o gado, quase todo mundo escolheu; foi feita uma ponta de gado na fazenda. Então foi isso que aconteceu. A roça mecanizada foi o segundo plano com a Funai, mas hoje, por exemplo, a Funai, nas suas recomendações, voltou a deixar fazer a roça de toco. Mas aí tem o papel da Brigada de Combate às Queimadas, formada pelos indígenas brigadistas que são treinados para controlar o fogo. Eles chegam na aldeia e fazem o levantamento de quando vão fazer a queima da roça, avisam a gente quando é o melhor momento, explicam como fazer um aceiro, e ajudam a queimar essa roça. Aí sim, os brigadistas vão lá na área da roça, com todos os seus equipamentos, fazem o aceiro, colocam fogo ali, queimam, plantam as sementes e as manivas ${ }^{7}$. A grande maioria dos indígenas Xerente, após o programa e ainda hoje, só pratica a roça de toco. Mas a participação dos brigadistas está sendo muito importante

\footnotetext{
${ }^{6}$ Feira de Tecnologia Agropecuária do Tocantins, acontece anualmente em Palmas, no mês de maio. ${ }^{7}$ Manivas: pequenos talos, rama da mandioca ou parte da rama destinada ao plantio.
} 
pela questão de preservar a natureza e impedir a queimada descontrolada na Terra Indígena. Tiveram outros projetos além da roça mecanizada, como o da avicultura, da piscicultura, suinocultura e da bovinocultura. Então todos estes projetos complementavam a Coordenação de Produção na parte de agricultura. O projeto de roça, por exemplo, foi do início até o final, durante os oito anos, mas agora o projeto de piscicultura, suíno e outros foram feitos no decorrer dos anos: se não dava certo passava para outro e assim foi feito. Então foi isso, por exemplo: a questão dos projetos de piscicultura, de galinhas. A piscicultura foi feita em uma aldeia onde fizeram os tanques escavados, levaram os peixinhos pequenos de $5 \mathrm{~cm}$ e a ração, e ensinaram a dar a ração. $O$ de galinhas foi feito para todas as aldeias, era um kit formado pelo galinheiro, com uma tela de mais ou menos dois metros de altura ao redor, mais a ração, e cada família recebeu 10 galinhas e um galo. A galinha tinha o bico cortado, não ciscava, só comia ração. Até as pessoas que tinham o hábito de criar acharam errado pela questão de impor que seria daquela forma. Então isso não funcionou, alguns até produziram e venderam o excedente, ovos, por exemplo. Alguns conseguiram vender ainda, mas não todos, e hoje deu um ponto final, não teve avanço. Na roça não tinha o que fazer para plantar mandioca e milho, era só arroz. Criar só com a ração não dá, porque era cara; quando acabava, como iam comprar mais ração? Sem dinheiro. Isso na época era a parte da administração. Para a parte da operacionalização, vinha recurso destinado pra administração, para o apoio logístico. Cada coordenação tinha o seu veículo. A Coordenação de Segurança Alimentar tinha veículo para a demanda deles, a Coordenação de Território, outro veículo, a Coordenação de Educação e Cultura, também, a gerência. Os conselheiros também aprovavam recursos para atender as demandas nas aldeias. Tinha índio que tinha carro que dava suporte e por isso tinha direito a usufruir de combustível ou peças. Então tiveram momentos em que nós gastamos muito recurso com a manutenção dos veículos. A questão de ceder combustível também era uma coisa incontrolável, por mais que nós quiséssemos controlar. Chegava um e pedia autorização para abastecimento, pois tinha trabalhado para o programa e tinha que receber o combustível. Por isso que às vezes falam assim, que nós indígenas, diante da administração, a gente fica dividido, fica em cima do muro, não sabendo se a gente atende à administração de uma ação que envolve leis, com as licitações, as normas, ou se atende aos aspectos que envolvem a nossa cultura, como, por exemplo, os mais velhos, os anciões. Na época eu tinha essa dificuldade de gerenciar [...], por exemplo, na hora que chega um velho, um ancião. A nossa cultura diz para respeitar, ouvir, atender, mas como? Aí chega um velho, um ancião: "oh, meu fio, eu vim a pé", aquele discurso, e você fala não. Ele não vai entender, então começa a briga, a discussão [...]. Na cultura, eu devo respeito a ele, por exemplo, então eu tinha essa dificuldade de, na época, fazer o que o conselho tinha aprovado para aplicar o recurso. Para o conselho, na prestação de contas que era feita todo o semestre, a gente prestava conta do que tinha sido gasto de 
janeiro a junho. Então, em julho a gente apresentava o recurso que tinha sido aplicado, aprovado. E aí lá no conselho, falavam: [...] olha, daqui pra frente vamos economizar, não vamos mais gastar combustível. Aí vem, o próprio conselheiro e aprova um recurso para manutenção dos veículos dos indígenas nas aldeias, até veículo particular, mas por ser índio, foi aprovado. Então, é uma coisa muito séria. Ainda tivemos que alugar carros, porque tinha carros que muitas vezes não compensava consertar. Às vezes alugávamos porque o que estava ali não tinha como consertar. $\mathrm{O}$ valor era muito alto. Então nós alugamos, desta forma, alguns carros pelo programa. E hoje o recurso acabou. Os carros também acabaram nas aldeias, porque não tinham mais manutenção.

Pesquisadora: Paulinho, gostaria que você me falasse sobre a multiplicação das aldeias nas Terras Indígenas Xerente. Para você, quais foram os motivos que proporcionou isso?

Paulo Waikarnase Xerente: Na época, em 2002-2003 eram doze aldeias, hoje tem 84 aldeias. Na época era um mil e pouco, quase dois mil indígenas. Hoje tem mais de três mil e oitocentos, então a população está aumentando. No decorrer do desenvolvimento do Programa de Compensação Ambiental Xerente, entre 2002 e 2008, realmente houve um aumento de doze para 34 aldeias. O Programa de Geração de Renda previa várias opções de projetos. As roças mecanizadas foram um projeto para todas as aldeias. Agora, para ter o projeto em sua aldeia, tinha que escolher, por exemplo: "eu quero na minha aldeia a bovinocultura"; o outro lá, "não, eu quero só galinha"; o outro, "eu quero só suíno". Então não era só um projeto de bovino para todo mundo. Então tinha uma escolha dentro do recurso previsto durante os anos de repasse de quase um milhão, dois milhões de reais anuais. Então, cada coordenação tinha o seu projeto, que apresentaria junto à comunidade indígena. A questão de criar aldeias surgiu no decorrer do desenvolvimento do programa. Os chefes das famílias diziam: "então nós vamos sair daqui e vamos fazer nossa aldeia e lá nós vamos ganhar o recurso deste projeto." Não era porque ali, naquele local, não estava mais dando certo; a ideia era sair para ganhar o recurso do projeto. Por isso, durante a execução do programa, passaram de 12 para 34, e de 34 para 70 aldeias. Foi um salto muito grande, mas até durante o último ano do programa, nós tínhamos 40 aldeias. A maioria das aldeias hoje é formada por famílias. Nós estamos aí, misturados: Funil, Salto, Porteira, Brejo Comprido, Rio do Sono, a maioria é formada por famílias, grande parte. A minha aldeia, por exemplo, é só meus pais e meus irmãos. Cada um com seu objetivo de lidar com a família. Mas isso, no decorrer do desenvolvimento do programa, não foi intenção de briga ou conflito; a questão foi mesmo de recurso financeiro. Eles diziam: "vou fazer uma aldeia, porque se eu não fizer eu não vou ganhar projeto, vou fazer isso". Então até quando nós terminamos o programa em 2008 - 2009, as coisas já tinham tomado 
essa outra dimensão, de separação, e hoje temos aproximadamente 84 aldeias.

Pesquisadora: Quais as principais aprendizagens desta experiência?

Paulo Waikarnase Xerente: Assumi e seria o meu primeiro emprego primeiro, já com uma responsabilidade muito grande de gerenciar o programa. O foco de todo mundo estava no programa, ninguém dava educação. Ninguém na Funai, por exemplo, nos preparou para a gestão do programa. Então o programa era tudo ali e eu estava ali no fogo cruzado. Realmente foi difícil: administrar onde a lei te envolve, onde a lei te responsabiliza, onde tem o procurador fiscalizando o recurso, onde tem a Funai disputando recurso, onde tem empreendedor que também quer o resultado deste recurso que foi repassado. Então isso para mim foi realmente uma preocupação muito grande. Pelo fato de ser repassado da empresa [Investco] para a Funai, a Polícia Federal estava de olho neste recurso, porque qualquer denúncia viraria uma bola de neve muito grande. Teve um momento lá que as pessoas falsificaram a requisição de combustível no meu nome. Porque cada um tinha a sua responsabilidade de autorizar o uso do combustível e eu tive que passar pelo processo de averiguação na Polícia Federal. Foi muito desgastante, mas graças a Deus não tive nada, saí sem sofrer nenhum processo administrativo. A parte da administração é muito perigosa, qualquer trabalho é de muita responsabilidade, principalmente quando tem muita gente olhando aquele recurso, onde nós aplicávamos centavo por centavo, por isso tínhamos que prestar contas. Nós temos as prestações de contas, são mais ou menos assim dessa grossura [ele indica com o dedo a grossura do documento], com tudo que foi gasto, nota fiscal, a data, o horário, o que foi o produto comprado, tudo discriminado ali na nota. Depois o contador e os conselheiros vão pegar cada nota e conferir aquilo tudinho, o que foi gasto. Por exemplo, eu nunca peguei esse recurso, 10 milhões de reais, nem sei que tanto monte é esse recurso. Mas para comprar esse microfone aqui, por exemplo, tem que fazer o orçamento, pegar valor menor, assim mandava, assim é o procedimento do órgão público. Então isso foi aprovado e aquilo não foi. Quando se acertava tudo, a empresa repassava o produto e nós pegávamos a nota. O recurso era da empresa e vinha pela Funai; nunca passou pelas nossas mãos. Também foi uma questão de grande relevância isso aí, pois o recurso não passava pelas nossas mãos, ia direto da empresa. Então foi muito bom, mas foi meio fogo cruzado, nós passamos por tudo isso aí. Foi uma experiência muito grande, que nos deu responsabilidade e ninguém é tão perfeito que talvez nunca errou. Talvez tenha erro na parte operacional do Programa, de avaliar, de ter experiência. Se fosse hoje a atribuição, não seria este Paulo administrador, seria outro Paulo totalmente diferente, mas a gente só vê depois que passou. Depois que passou um tempo, se faz outra avaliação, às vezes autocrítica. Às vezes você foi criticado, mas leva como crítica construtiva, não deixa de ser construtiva. Muitas críticas que às vezes eu 
ficava achando ruim, agora refletindo, lembrando, eu sei porque alguém me criticou ali naquele momento. E hoje está servindo para mim lá na frente. $E$ isso é muito bom. A comunidade pensou, sim, que talvez nunca fosse acabar este recurso. Era para gerar um projeto que se tornasse autossustentável. Mas não foram todos os projetos não deram certo, em alguns casos foi só mesmo questão da Coordenação num momento, já passavam para outro projeto e aquele ficava para trás. E aí a comunidade ficou numa situação de muita dependência do recurso financeiro, não tem alguém que deste Programa possa dizer: "eu fiz isto aqui e até hoje nós temos". Não tem. Somente a bovinocultura, que foi a última que saiu dali, e que algumas aldeias ainda têm ativa. Então a UHE Lajeado, hoje nós temos este impacto que está acontecendo na parte cultural, na parte social. Teve uma influência muito grande na questão da organização do povo Xerente. Durante estes anos, tivemos pontos positivos e pontos negativos. Os pontos positivos são que na época tinha recurso, e muito barulho dentro da Terra Indígena, tinha projeto na área da produção, na área do meio ambiente, na parte da cultura. Então isso no decorrer de oito anos. Enquanto as aldeias das outras etnias do Tocantins, como Javaé, Karajá não tinham este projeto. Só que depois temos os pontos negativos que, por exemplo: hoje se nós avaliarmos o que o programa fez na área indígena, praticamente não fez nada. Todo apoio operacional, estrutura logística que nós tivemos na época do projeto, hoje não tem mais nada. Trator, carro, caminhão, tem um só nome, que realmente teve esse apoio logístico, e a parte agrícola, que era as roças mecanizadas, foram feitas no cerrado e hoje nós temos aí várias áreas desmatadas. Estão se recompondo gradativamente. A minha preocupação é com a microbacia na Terra Indígena Xerente, por exemplo: hoje o Rio Piabanha, a cabeceira dele secou o ano passado, este ano a mesma coisa, não é? O Rio Piabanha que faz divisa com Tocantínia e a aldeia também está sendo ameaçado, por que isso? O estudo poderia, às vezes, melhorar os recursos hídricos, o lençol freático que está baixo. Então isso é linguagem mais ambiental, eu tenho certeza que isso vai estar afetando o povo Xerente diretamente, durante o decorrer da caminhada da Terra indígena no tempo. Há também a redução da capacidade produtiva da comunidade, com a perda das roças de vazante, que realmente as pessoas que moraram tanto na parte do Rio Tocantins e também ali no Rio do Sono. Mas principalmente no Tocantins, as aldeias, os índios que faziam as suas roças de vazante onde plantava arroz, milho, abóbora, melancia, feijão, hoje não têm. Pode até ter, mas só que não dá resultado. Porque antes enchia o Rio Tocantins, até certo ponto, ali a margem do Tocantins adubava, a enchente automaticamente adubava, secava e aí os índios faziam a sua roça. Hoje enche, até fora da época que a gente é acostumado de ver, no mês de fevereiro, janeiro, março enche o Rio Tocantins. Hoje meio de julho, às vezes, nós estamos vendo um barco atravessando de Tocantínia para Miracema, lá no meio do rio. Você vai a pé até Miracema, dá pra ir a pé. Na volta, quando você voltar, duas horas da tarde ou três horas, o rio está cheio, mas não tinha água antes, 
o homem governa a água, né? Então isso, o homem teve esse impacto, das perdas das roças de vazante na comunidade indígena, que foi um ponto negativo. Redução da produção da proteína animal, principalmente pescado. Então nós estamos vivendo num reservatório de água, um tanque de piscicultura que foi feito com o próprio esforço do homem - a barragem. Tem aí várias barragens pra cima. Então hoje a pescaria teve uma redução muito grande no Tocantins, principalmente ali para o povo Xerente. E outra, a criação de muitas aldeias, aumentando o número de aldeias, diminuindo a população de cada uma delas, provoca, assim, impactos sociais na vida do povo. Também na vida social tem impacto muito grande essa barragem. Por exemplo, essa proposição de ocupar a área indígena é uma forma alarmante, por outro lado é bom, porque realmente hoje cada um tem sua área nas aldeias. Agora para atendimento na área de educação, na área da saúde ou outra área do projeto fica difícil, porque as coisas para infraestrutura das aldeias são difíceis de se conseguir. Os mais velhos, as pessoas que participaram diretamente, alguns já partiram para a eternidade. Ficou nesse meio, um ponto de interrogação: isso foi bom para os Xerente? Essa construção de grande obra, de vulto nacional, que seria a barragem UHE Lajeado, o que trouxe para os Xerente? Outra questão para o Xerente é com relação ao recurso financeiro em si, foi uma coisa que realmente ficou uma lacuna que não vai se fechar. Temos esperança que um dia os órgãos fiscalizadores possam analisar melhor que o impacto da usina perante a comunidade indígena não foi apenas durante 9 ou 10 anos. Então é daqui pra frente que realmente o impacto está surgindo, e é preocupante para o povo Xerente.

Pesquisadora: Foi difícil aprender o processo da gestão da coisa pública?

Paulo Waikarnase Xerente: Foi difícil, a gente tem dificuldade até, às vezes, de falar o português, então aí já começa a nossa dificuldade. Imagina a gente já deparar com engenheiro agrônomo, engenheiro ambiental, advogados. A gente está quase sempre querendo ficar de igual para igual. Mas é difícil, não é fácil, não, da pessoa se deparar com o Programa, com um recurso de 10 milhões de reais. Uma responsabilidade muito grande, mas a gente está se atualizando, principalmente na área da educação, tem os professores, tem muitos indígenas formados na parte da educação. Envolver esses parceiros indígenas, na área da saúde e educação. Então, assim, parceria como um todo são bem vindas para nos fortalecer, então toda a dificuldade pode se romper neste momento de questão da gestão administrativa.

Pesquisadora: Que mensagem você deixaria para outros povos indígenas que estão passando ou passarão por um processo de compensação e/ou mitigação de impactos de grandes obras? 
Paulo Waikarnase Xerente: Analisar o futuro, porque nós passamos, nossa vida é passageira. Muitas vezes lutamos pelo futuro do povo, às vezes nem conseguem entrar no projeto, às vezes nem consegue finalizar o projeto. Agora, o povo poderia ter o gosto de como administrar um Programa. Lógico, pegar um indígena qualificado, com responsabilidade, que não adianta nada pegar qualquer um e deixar ali, no meio do caminho. Às vezes, comparando com a corda de buriti nas costas, de repente no meio do caminho cai, e vai ser preciso todo mundo parar para levantar de novo. E se puder aprender com os erros. Às vezes é natural, errar uma vez e buscar corrigir o erro. Priorizar a capacidade que nós temos hoje, de gerenciar o recurso e um programa. Nós temos capacidade para isso, mas nós temos que cuidar com as influências políticas, pois lá na frente os próprios indígenas podem se enfrentar e discutir. A mensagem que eu deixaria é priorizar os parceiros, como Funai, Cimi, universidades, instituições como parceiras. Pegar nossos parceiros positivos, que nós já temos e, com certeza, poderíamos ter um avanço muito grande para a comunidade indígena, onde nós estamos sendo atacados pelo Governo Municipal, Estadual e Federal. Nós temos a nossa ferramenta de fortalecer o nosso meio de convivência indígena. Hoje, o indígena mora na aldeia, as pessoas que trabalham com a gente estão no período de trabalho do contrato, depois que terminar, vão embora. Então vão ficar os próprios índios. Pegar este parceiro e fortalecer as associações, de fazer cursos de capacitações, de manejo de recurso, tudo isso é ponto positivo para nós. Minha mensagem que deixo é a gente fortalecer nossa convivência interna.

\section{Considerações Finais}

Ao concluir a leitura da entrevista, percebe-se que o gerente indígena do Procambix carrega um fardo muito grande em decorrência da cobrança exercida pela sua própria comunidade, a partir dos resultados do Programa. A sua grande dificuldade foi no processo administrativo e burocrático exercida pela ação de gestão do bem público. Apesar do recurso financeiro não ser proveniente de recursos da União e sim da empresa privada Investco, ele foi gerido pelas normas da administração pública, seguindo a legislação pertinente aos contratos administrativos, os procedimentos de licitação e ou dispensa destes processos. A falta de experiência no processo de licenciamento ambiental e ações de mitigação dos impactos, pelos atores das instituições envolvidas, pode ter colaborado para o desfecho dos resultados alcançados pelo Programa de Compensação Ambiental Xerente. Este aspecto fica evidente: acabado o recurso financeiro estabelecido na negociação, a empresa não tem mais responsabilidade sobre os impactos ambientais que estão se intensificando sobre a Terra Indígena após estes anos de barramento do Rio Tocantins. 


\section{Referências Bibliográficas}

DE PAULA, Luís Roberto. Dinâmica Faccional Xerente: esfera local e processos sociopolíticos nacionais e internacionais. 2000. Dissertação de Mestrado em Antropologia Social, FFLCH/USP. São Paulo.

MAYBURY-LEWIS, David. Akwen savante society. Oxford, Clarendon Press, 1965. Trad. brasileira: Rio de Janeiro, Livraria Francisco Alves, 1984.

NIMUENDAJÚ, C. The Serente. Los Angeles: The Southwest Museum, 1942.

SILVA, Cleube Alves. Juntando Mundos: conflito, aldeamento, estagnação e renascimento Xerente nos séculos XIX e XX. In. VII ENCONTRO REGIONAL DA ANPUH-GO: Minorias: Identidade e Memória, 2000, Goiânia. Caderno de resumos, Goiânia: UFG, 2000. p. 11.

O olhar do contato: uma discussão da relação entre o colonizador e as comunidades indígenas do norte da Capitania de Goiás no século XVIII. 2002. $40 \mathrm{f}$. Monografia (Especialização em História Social Brasileira), Universidade Estadual do Tocantins - UNITINS, 2002.

. Do buriti ao capim dourado: mudança cultural ou dinâmica histórica no trabalho com artesanato entre os Xerente. Digitado, inédito, 2005.

Confrontando mundos: Os Xerente, Xavante, Xakriabá e Akroá e os contatos com os conquistadores da Capitania de Goiás (1749-1851).2006. 163 f. Dissertação (Mestrado em História), Universidade Federal da Grande Dourados, Dourados, 2006.

SILVA, Cleube Alves; GIRALDIN, Odair. Ligando Mundos: relação entre Xerente e a sociedade circundante no século XIX. Boletim do Museu Paraense Emilio Goeldi série Antropologia, Belém, v. 18, n. 1, p. 43-58, jul. 2002.

O índio ou o ouro: os contatos entre Akwen e os conquistadores no norte da Capitania de Goiás (hoje Tocantins): 1749-1811. Territórios e Fronteiras, Cuiabá, v. 5, n. 2, p. 157-170, jul./dez. 2005.

SILVA, Reijane Pinheiro; SOUSA Apoliana Ribeiro de. Alcoolismo e uso do álcool entre os Akwen Xerente do Tocantins: a perspectiva indígena. RBSE - Revista Brasileira de Sociologia da Emoção, v. 14, n. 42, p. 109-120, 2015. ISSN: 1676-8965. 2015.

XERENTE, Paulo Karnãse. Projeto Gestão Participativa da Biodiversidade em Terras Indígenas atingidas por barragens hidrelétricas na Amazônia brasileira. Porto Nacional. Núcleo de Estudos em Assuntos Indígenas - NEAI da Universidade Federal do Tocantins, Tocantins. 26 out. 2016. Entrevista concedida sob coordenação do 
prof $^{\circ} \operatorname{Dr}^{\circ}$ Odair Giraldin.

Projeto de Tese Análise do processo de elaboração, execução e resultados do programa de Compensação Ambiental de Usinas Hidrelétricas: a Usina de Lajeado. Palmas, Núcleo de Pesquisa Aplicada à Pesca e Aquicultura Norte 5 - NUPA Norte 5, Instituto Federal de Educação, Ciência e Tecnologia do Tocantins (IFTO) Campus Palmas, Tocantins 11 de agosto de 2017. Entrevista a Sylvia Salla Setubal.

Recebido em: 30/11/2017 * Aprovado em: 03/09/2018 * Publicado em: 27/06/2019 